10 Roth MD, Connett JE, D'Armiento JM, et al. Feasibility of retinoids for the treatment of emphysema study. Chest 2006; 130: 1334-1345.

11 Paul CC, Mahrer S, Tolbert M, et al. Changing the differentiation program of hematopoietic cells: retinoic acid-induced shift of eosinophil-committed cells to neutrophils. Blood 1995; 86: 3737-3744.

12 Viglio S, Annovazzi L, Luisetti M, et al. Progress in the methodological strategies for the detection in real samples of desmosine and isodesmosine, two biological markers of elastin degradation. J Sep Sci 2007; 30: 202-213.
13 Kim EY, Battaile JT, Patel AC, et al. Persistent activation of an innate immune response translates respiratory viral infection into chronic lung disease. Nat Med 2008; 14: 633-640.

14 Saha S, Mistry V, Siva R, et al. Induced sputum and bronchial mucosal expression of interleukin-13 is not increased in chronic obstructive pulmonary disease. Allergy 2008; 63: 1239-1243.

DOI: $10.1183 / 09031936.00105309$

\title{
Diffuse idiopathic pulmonary neuroendocrine hyperplasia, chronic eosinophilic pneumonia, and asthma
}

\section{To the Editors:}

Herein we report the progression of irreversible airflow obstruction in a patient with diffuse idiopathic pulmonary neuroendocrine cell hyperplasia (DIPNECH). Following an episode of chronic eosinophilic pneumonia associated with raised sputum substance $\mathrm{P}$ and infiltration of the interstitum and alveolar spaces with eosinophils, the fixed airflow limitation became variable (i.e. asthma), requiring treatment with inhaled corticosteroids and long-acting $\beta$-agonists.

A number of airway diseases, such as smoker's bronchitis, emphysema, asthma, bronchiolitis and bronchiectasis, can lead to chronic airflow limitation [1]. However, variability and reversibility of airflow limitation is only observed in asthma. Inflammatory cell infiltration of the airway, particularly with eosinophils, may be one of the mechanisms of variable airflow limitation [2]. Although the natural history of eosinophilic bronchitis is not well known, it is believed that it may lead to chronic irreversible airflow limitation [3]. However, it is unusual for chronic irreversible airflow limitation to show variability and improvement in airway calibre following treatment with corticosteroids. This case report describes the changes in lung function and response to treatment of a patient with chronic airflow limitation due to smoker's bronchitis and DIPNECH following eosinophilic inflammation of the airway and the interstitium. The case also highlights the importance of measuring airway inflammation in the management of airway diseases.

A 65-yr-old female with a history of hypercholesterolemia, vertebral osteoarthritis, gall stone disease and endometriosis but no previous respiratory illness, except a mild intermittent cough for the past 4 yrs, presented with fever, night sweats, worsening cough and weight loss of $6.8 \mathrm{~kg}$ (15 lbs). She did not have muscle or joint aches, a skin rash or bowel symptoms. She appeared pale and had inspiratory crackles in her left axillary region. After accumulating a 12 pack-yr smoking history, she had quit smoking $15 \mathrm{yrs}$ earlier. She had immigrated to Canada from Germany in 1961. She did not keep any pets at home, had not recently travelled outside of Ontario (Canada) and did not have any known risk factors for HIV infection. She was not on any medications that could cause adverse effects on the lung.

A blood count showed anaemia, lymphopenia, mild eosinophilia $\left(1.0 \times 10^{9} \cdot \mathrm{L}^{-1}\right)$ and thrombocytosis. An auto-antibody profile and fungal and avian precipitins were negative. Skin prick tests with common aeroallergens including aspergillus were also negative. A tuberculin test showed a 20-mm induration. A chest radiograph performed at the onset of her illness showed soft fluffy infiltrates of both upper zones which became extensive 1 week later. At the time of assessment in our clinic (Firestone Institute for Respiratory Health, Hamilton, Ontario), a chest radiograph showed almost complete resolution of the right upper-zone infiltrate and further extension of the infiltrate in the left lung to the mid-zones. A highresolution computed tomography (HRCT) scan of the chest showed ground-glass opacities in both upper lobes and extensive infiltrates with air bronchogram in the left lower lobe extending to the periphery of the lung. Sputum and bronchoalveolar lavage fluid examination did not grow any pathogenic organisms. Substance $\mathrm{P}$ in sputum supernatant (measured by radioimmunoassay using antisubstance $\mathrm{P}$ antibody (Peninsula Laboratories, San Carlos, CA, USA), as previously described [4]) was elevated at $1,210 \mathrm{pg} \cdot \mathrm{mL}^{-1}$ (normal $<400 \mathrm{pg} \cdot \mathrm{mL}^{-1}$ ). Spirometry showed a mixed obstructive and nonobstructive ventilatory pattern without variable airflow obstruction (table 1).

Histopathological examination of a video-assisted thorascopic biopsy from the left lower lobe showed two distinct disease processes. The alveoli were filled with abundant eosinophils and some fibrinous exudate, which extended into the related respiratory bronchioles and showed evidence of organisation. The muscular pulmonary arteries and the veins of the affected areas showed low-grade non-necrotising vasculitis and scant infiltration by eosinophils and lymphocytes. Examination for fungi by Grocott staining was negative. These findings were consistent with chronic eosinophilic pneumonia (fig. 1a). The other finding was proliferation of neuroendocrine cells, which stained positive for chromogranin $\mathrm{A}$ and stomatophysin in 
TABLE 1 Time course of clinical and physiological abnormalities

\begin{tabular}{|c|c|c|c|c|}
\hline FEV1 (pred) L & $1.4(2.5)$ & $1.6(2.5)$ & $1.5(2.5)$ & $1.6(2.4)$ \\
\hline FEV1/VC & 64 & 67 & 63 & 70 \\
\hline FEV1 bronchodilator reversibility \% & 0 & 0 & 20 & 2 \\
\hline $\mathrm{PC}_{20}$ methacholine $\mathrm{mg} \cdot \mathrm{mL}^{-1}$ & 7.8 & Not checked & Not checked & 2.2 \\
\hline Substance $P^{\circ} \mathrm{pg} \cdot \mathrm{mL}^{-1}$ & 1210 & Not checked & Not checked & 82 \\
\hline Pattern of airway disease & $\begin{array}{c}\text { Mixed obstructive + nonob- } \\
\text { structive }\end{array}$ & Obstructive & Variable obstructive & Variable obstructive \\
\hline
\end{tabular}

Data are presented as per cent, unless otherwise stated. FEV1: forced expiratory volume in $1 \mathrm{~s}$; pred: predicted; VC: vital capacity; PC20: provocative concentration causing a $20 \%$ fall in FEV1. ${ }^{\#}$ : normal $<1.1 \%$; ${ }^{*}$ : normal level is $<400 \mathrm{pg} \cdot \mathrm{mL}^{-1}$

relation to membranous bronchioles, some of which showed fibrosis with narrowing and obliteration. This was consistent with a diagnosis of DIPNECH (fig. 1b).

The patient showed remarkable clinical and radiological improvement following treatment with prednisone for a total period of 6 months. The proportion of eosinophils in induced sputum was $1 \%$ and the blood eosinophil count had decreased to $0.2 \times 10^{9} \cdot \mathrm{L}^{-1}$. Although the post-bronchodilator forced expiratory volume in $1 \mathrm{~s}$ (FEV1) improved to $1.6 \mathrm{~L}$, she had mild impairment of gas exchange (diffusing capacity $58 \%$ predicted, but normal when adjusted for the alveolar volume) and slightly reduced lung volume (72\% pred). The exercise capacity was also in the normal range but it was low. She remained symptom free for $1 \mathrm{yr}$ before she noticed wheezing on exertion and a recurrence of her cough. The FEV1 and vital capacity (VC) were $1.5 \mathrm{~L}$ and $2.4 \mathrm{~L}$, respectively, improving to $1.8 \mathrm{~L}$ and $2.6 \mathrm{~L}$, respectively, after inhalation of $200 \mu \mathrm{g}$ of salbutamol. The blood eosinophil count was normal $\left(0.2 \times 10^{9} \cdot \mathrm{L}^{-1}\right)$, but the proportion of eosinophils in sputum had risen to $6 \%$ (normal $<1.1 \%$ ). A HRCT scan of the chest did not show alveolitis. A few small nodules were seen to be
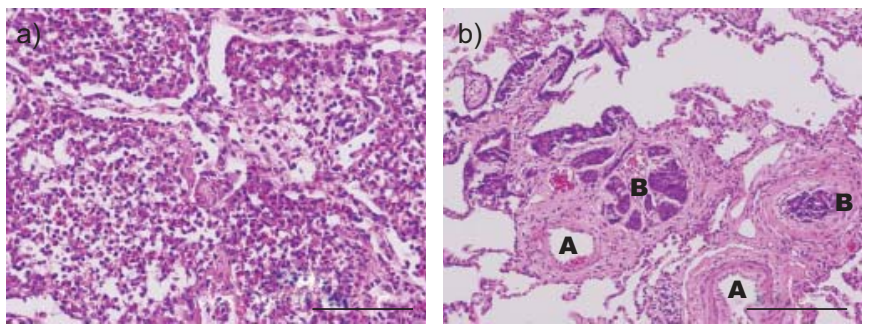

FIGURE 1. a) Histopathological examination showing chronic eosinophilic pneumonia. The alveoli contain abundant eosinophils with characteristic bilobed nuclei and prominent coarse cytoplasmic granules (Haematoxylin and eosin stain). b) Histopatholigical examination showing diffuse pulmonary neuroendochrine cell hyperplasia. Two membranous bronchioles (B) adjacent to the accompanying small muscular pulmonary arteries (A) show a proliferation of dark-stained neuroendochrine cells with associated narrowing or obliteration of the lumens. Small clumps of proliferated neuroendochrine cells are located in the peribronchiolar tissue of the left-hand bronchiole (Haematoxylin and eosin stain). Scale bars $=200 \mu \mathrm{m}$. scattered over both lung fields. She was started on a combination of inhaled fluticasone $(250 \mu \mathrm{g})$ and salmeterol $(50 \mu \mathrm{g})$ twice daily with remarkable improvement in symptoms and lung function (FEV1/VC 1.7/2.7 L) without further bronchodilator improvement. She has remained symptom free during 4 yrs of follow-up. Sputum substance P was $82 \mathrm{pg} \cdot \mathrm{mL}^{-1}$ (table 1).

This report highlights two interesting observations. First, we describe the first reported association of DIPNECH and chronic eosinophilic pneumonia and speculate that products of neuroendocrine cells, such as substance $\mathrm{P}$, may have contributed to the development of lung eosinophilia. Secondly, we describe an unusual progression of airway physiology; eosinophilic inflammation of the airway and the alveolar spaces. This resulted in marked variability and bronchodilator reversibility in the airflow limitation requiring monitoring of airway inflammation using induced sputum to guide maintenance therapy with an inhaled corticosteroid and a long-acting bronchodilator.

Reactive pulmonary neuroendocrine cell hyperplasia has been observed in people living at high altitudes [5] and individuals living with other pulmonary conditions, particularly bronchiectasis, chronic lung abscesses, chronic obstructive pulmonary disease and pulmonary interstitial fibrosis [6]. However, DIPNECH has been defined as a precursor to carcinoid tumours [7], and is mostly described in middle-to-older aged, nonsmoking females [8-10]. It is plausible that hyperplasia of neuroendocrine cells may have been triggered in our patient by smoker's bronchitis or it may be idiopathic. It is difficult to speculate if the eosinophilic pneumonia preceded or succeeded the development of DIPNECH. We believe that smoker's bronchitis, diffuse neuroendocrine hyperplasia and eosinophilic pneumonia all contributed to the mixed airway and interstitial disease in this patient (fig. 2).

It is well recognised that eosinophilic bronchitis and eosinophilic pneumonia are responsive to treatment with corticosteroids. Indeed, this is reflected in the clinical, radiological and physiological improvement observed in our patient. The steroid-responsive component of the airway disease resulted 


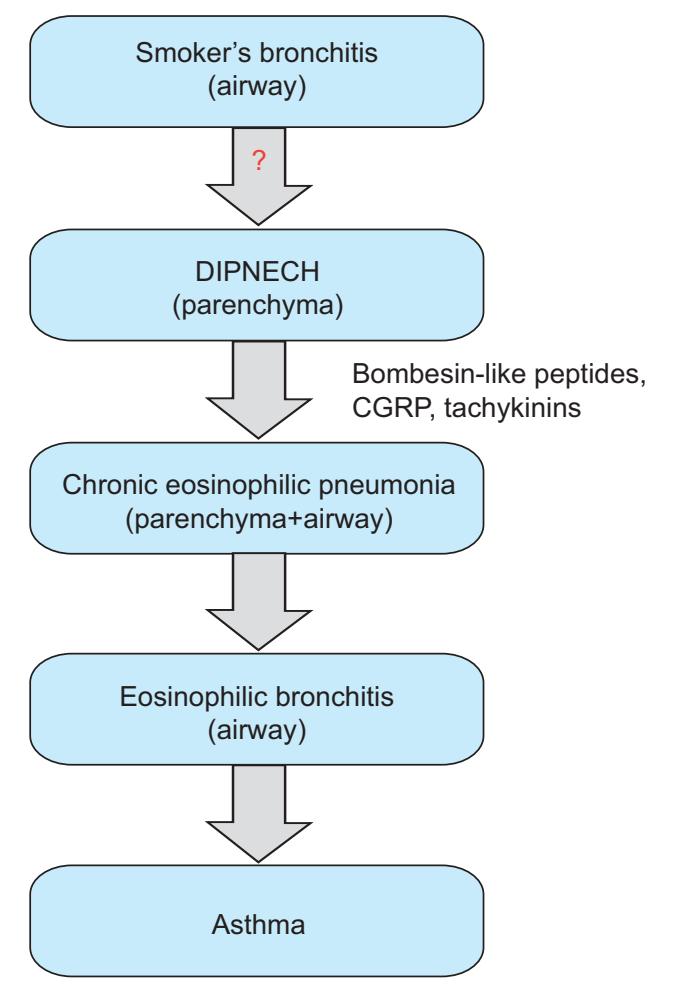

FIGURE 2. Speculative schematic diagram of the progression of physiological and pathological abnormalities. DIPNECH: diffuse idiopathic pulmonary neuroendocrine cell hyperplasia; CGRP: calcitonin gene-related peptides.

in partial improvement in FEV1. There was no significant change in the diffusion coefficient. The subsequent worsening of airflow limitation that showed bronchodilator reversibility, which by definition is asthma [11], is unusual. It is recognised that a large proportion of patients with chronic eosinophilic pneumonia may have asthma preceding the illness [12]. However, it is rare for asthma to develop after 6 months of treatment with prednisone for eosinophilic pneumonia, particularly when the patient did not have peripheral blood eosinophilia. It is likely that an eosinophilic inflammation localised to the airway resulted in the variable airflow limitation. This was detected by examining cell counts in cytospins prepared from dithiothreitol dispersed sputum induced with hypertonic saline. This is a reproducible and reliable method to assess airway inflammation and is clinically useful in the management of airway diseases and in assessing responses to treatment [13].

A tantalising speculation for the development of interstitial and airway eosinophilia and asthma is DIPNECH. The secretory products of from these cells, such as bombesin-like peptides, tachykinins and calcitonin gene-related peptides, may cause airway eosinophilia and bronchoconstriction [1418]. Raised levels of substance $P$ in the patient's sputum supernatant allowed us to speculate that the hyperplastic neuroendocrine cells may be responsible for airway eosinophilia [19] and variable airflow limitation.

In summary, we report the first association of DIPNECH and chronic eosinophilic pneumonia and its progression to eosinophilic bronchitis and asthma.

\section{M.S. Sanaee, P.M. O'Byrne and P. Nair}

*Firestone Institute for Respiratory Health, St. Joseph's Healthcare and Dept of Medicine, McMaster University, Hamilton, ON, Canada.

Correspondence: P. Nair, Firestone Institute for Respiratory Health, St. Joseph's Healthcare, 50 Charlton Avenue East, Hamilton, ON, L8N 4A6, Canada. E-mail: parames@mcmaster.ca

Support Statement: P. Nair is supported by a Canada Research Chair in Airway Inflammometry.

Statement of Interest: A statement of interest for P.M.O'Byrne can be found at www.erj.ersjournlas.com/misc/statements.dtl

Acknowledgements: We would like to thank M. Kay for the pathology reports and J. Urschel and G. Cox (all McMaster University, Hamilton, ON, Canada) for assisting in the management of the patient.

\section{REFERENCES}

1 Celli BR, MacNeeW, Agusti A, et al. Standards for the diagnosis and treatment of patients with COPD: a summary of the ATS/ERS position paper. Eur Respir J 2004; 23: 932-946.

2 Busse WW, Lemanske RF. Asthma. N Engl J Med 2001; 344: 350-362.

3 Berry MA, Hargadon B, McKenna S, et al. Observational study of the natural history of eosinophilic bronchitis. Clin Exp Allergy 2005; 35: 598-601.

4 Pizzichini MM, Pizzichini E, Parameswaran K, et al. Nonasthmatic chronic cough: no effect of treatment with an inhaled corticosteroid in patients without sputum eosinophilia. Can Respir J 1999; 6: 323-330.

5 Armas OA, White DA, Erlandson RA, et al. Diffuse idiopathic pulmonary neuroendocrine proliferation presenting as interstitial lung disease. Am J Surg Pathol 1995; 19: 963-970.

6 Ge Y, Eltorky MA, Ernst RD, et al. Diffuse idiopathic pulmonary neuroendocrine cell hyperplasia. Ann Diag Pathol 2007; 11: 122-126.

7 Brambilla E, Travis WD, Colby TV, et al. The new World Health Organization classification of lung tumours. Eur Respir J 2001; 18: 1059-1068.

8 Swigris J, Ghamande S, Rice TW, et al. Diffuse idiopathic neuroendocrine cell hyperplasia: an interstitial lung disease with airway obstruction. J Bronchol 2005; 12: 62-65.

9 Aguayo SM, Miller YE, Waldron Jr JA, et al. Idiopathic hyperplasia of pulmonary neuroendocrine cells and airways disease. $N$ Engl J Med 1992; 327: 1285-1288.

10 Davies SJ, Gosney JR, Hansell DM, et al. Diffuse idiopathic pulmonary neuroendocrine cell hyperplasia: an under-recognised spectrum of disease. Thorax 2007; 62: 248-252.

11 Hargreave FE, Parameswaran K. Asthma, COPD and bronchitis are just components of airway diseases. Eur Respir J 2006; 28: 264-267.

12 Marchand E, Cordier JF. Idiopathic chronic eosinophilic pneumonia. Sem Resp Crit Care Med 2006; 27: 134-141.

13 Parameswaran K, Hargreave FE. The use of sputum cell counts to evaluate asthma medications. Br J Clin Pharmacol 2001; 52: 121-128.

14 Solway J, Leff AR. Sensory neuropeptides and airway function. J Appl Physiol 1991; 71: 2077-2087.

$15 \mathrm{O}^{\prime}$ Connor TM, O'Connel J, O'Brien DI, et al. The role of substance P in inflammatory disease. J Cell Phys 2004; 201: 167-180.

16 Springer J, Geppetti P, Fischer A, Groneberg DA. Calcitonin generelated peptide as inflammatory mediator. Pulmonary Pharm Therapeutics 2003; 16: 121-130. 
17 Joos GF, De Swert KO, Schelfhout V, et al. The role of neural inflammation in asthma and chronic obstructive pulmonary disease. Ann NY Acad Sci 2003; 992: 218-230.

18 Joos G, Pauwels R, Van Der Straten M. The effect of inhaled substance $\mathrm{P}$ and neurokinin $\mathrm{A}$ on the airways of normal and asthmatic subjects. Thorax 1987; 42: 779-783.
19 Wiedermann FJ, Kahler CM, Reinisch N, et al. Induction of normal human eosinophil migration in vitro by substance P. Acta Haematol 1993; 89: 213-215.

\section{What is the optimal dosage of linezolid in treatment of complicated multidrug-resistant tuberculosis?}

\section{To the Editors:}

In a retrospective study, MigLIORI et al. [1] have elegantly shown that linezolid $600 \mathrm{mg}$ daily or twice daily added to an individualised multidrug regimen was efficacious in treating multidrug-resistant tuberculosis (MDR-TB). Once-daily dosing was associated with less major adverse effects than twice-daily dosing, corroborating the results of an earlier study in South Korea [2]. As a result of the potentially serious side-effects, MigLIORI et al. [1] have appropriately recommended reserving linezolid treatment for the most complicated cases of MDR-TB. We concur with these views and would like to share our experience regarding the use of linezolid $800 \mathrm{mg}$ once daily in the treatment of extensively drug-resistant tuberculosis (XDRTB) and fluoroquinolone-resistant MDR-TB.

Table 1 shows the clinical profiles of two patients. The first is a 41-yr-old male smoker with smear-positive XDR-TB following a long history of treatment for chronic tuberculosis overseas. His chest radiograph initially showed an extremely large cavity involving the right upper lobe and the apical segment of the right lower lobe. Despite apparent sputum culture conversion after treatment for 12 weeks, drug susceptibility testing (DST) revealed an increase in the minimum inhibitory concentration of linezolid against Mycobacterium tuberculosis from $0.5 \mathrm{mg} \cdot \mathrm{L}^{-1}$ to $4 \mathrm{mg} \cdot \mathrm{L}^{-1}$ for the last positive-culture isolate after 2 months of therapy. Besides reflecting the activity of the oxazolidinones against $M$. tuberculosis, this phenomenon might represent transitional bacillary resistance prior to bacteriological conversion from positivity to negativity. The second patient is a $60-y r-$ old diabetic male with smear-positive fluoroquinolone-resistant MDR-TB and a high possibility of sequestered lung disease due to a thick-walled cavity in the left upper lobe. He has received two main periods of linezolid administration of varying dosages; the second period is still ongoing. Compared to the experience with linezolid $600 \mathrm{mg}$ twice-daily dosing, his tolerance was better with $800 \mathrm{mg}$ once daily. In addition, to date, there is no evidence of bacillary resistance to linezolid from serial DST. Both patients have apparently achieved lowering of bacillary load after administration of linezolid, together with shrinkage of cavities even when the dose of linezolid was $800 \mathrm{mg}$ once daily. Surgery after achieving sputum culture conversion was contemplated in both cases, but the thought was abandoned by patients and surgeons in view of the high risk of post-operative morbidity and mortality. However, without surgery, reversion of bacteriological status to positivity would be very likely.

Our data corroborate previous findings of good diffusion of linezolid into tuberculosis cavities [3]. An in vitro pharmacodynamic model in Bacillus anthracis has suggested that an optimised once-daily dose of linezolid might prevent emergence of drug resistance, in addition to conferring antibacterial efficacy [4]. Linezolid has a reasonably low mutant prevention concentration that would theoretically help to restrict the development of mycobacterial resistance [5]. Thus, more exploration is required to delineate an optimal dose of linezolid in the treatment of "complicated" or "difficult" MDR-TB.

\section{W.W. Yew*, K.C. Chang" and C.H. Chau*}

*Tuberculosis and Chest Unit, Grantham Hospital, Aberdeen, and "Dept of Health, Tuberculosis and Chest Service, Wanchai, Hong Kong.

Correspondence: C.H. Chau, Tuberculosis and Chest Unit, Grantham Hospital, 125 Wong Chuck Hang Road, Aberdeen, Hong Kong. E-mail: chau_ch@hotmail.com

Statement of Interest: None declared.

\section{REFERENCES}

1 Migliori GB, Eker B, Richardson MD, et al. A retrospective TBNET assessment of linezolid safety, tolerability and efficacy in multidrugresistant tuberculosis. Eur Respir J 2009; 34: 387-393.

2 Park IN, Hong SB, Oh YM, et al. Efficacy and tolerability of dailyhalf dose linezolid in patients with intractable multidrug-resistant tuberculosis. J Antimicrob Chemother 2006; 58: 701-704. 